Cahiers $d u$ MONDE RUSSE

\section{Cahiers du monde russe}

Russie - Empire russe - Union soviétique et États indépendants

$46 / 4 \mid 2005$

L'invention d'une politique humanitaire

\title{
S. V. Karpenko, ed., Meždu Rossiej i Stalinym | Michael Kellog, The Russian Roots of Nazism
}

\section{Sophie Cœuré}

\section{(2) OpenEdition}

Journals

Édition électronique

URL : https://journals.openedition.org/monderusse/2900

DOI : $10.4000 /$ monderusse. 2900

ISSN : $1777-5388$

\section{Éditeur}

Éditions de l'EHESS

\section{Édition imprimée}

Date de publication : 1 décembre 2005

Pagination : 979-982

ISBN : 2-7132-2057-2

ISSN : $1252-6576$

Référence électronique

Sophie Cœuré, «S. V. Karpenko, ed., Meždu Rossiej i Stalinym | Michael Kellog, The Russian Roots of Nazism », Cahiers du monde russe [En ligne], 46/4 | 2005, mis en ligne le 29 juin 2009, consulté le 03 septembre 2022. URL : http://journals.openedition.org/monderusse/2900 ; DOI : https://doi.org/ 10.4000/monderusse. 2900

Ce document a été généré automatiquement le 3 septembre 2022

Tous droits réservés 


\title{
S. V. Karpenko, ed., Meždu Rossiej i Stalinym | Michael Kellog, The Russian Roots of Nazism
}

\author{
Sophie Cœuré
}

\section{RÉFÉRENCE}

\section{S. V. KARPENKO, ed., Meždu Rossiej i Stalinym. Rossijskaja emigracija i vtoraja}

mirovaja vojna. Moscou : RGGU, 2004, 346 p. (Russkie bez otečestva)

Michael KELLOG, The Russian Roots of Nazism. White Émigrés and the Making of

National Socialism, 1917-1945. Cambridge : Cambridge University Press, 2005, 327 p.

(New Studies in European History)

1 Ces deux ouvrages viennent, chacun à sa manière, enrichir les connaissances sur l'histoire politique de l'émigration dite «russe» ou «blanche » (c'est-à-dire issue de l'empire tsariste) des années 1920 à 1945. Ils ont pour point commun de mettre l'accent sur la grande diversité des solutions idéologiques et pratiques apportées par les mouvements et les partis des émigrations implantées en Europe, mais aussi en Mandchourie ou aux États-Unis, à la situation géopolitique créée par l'arrivée des bolcheviks au pouvoir, en fonction d'enjeux nationaux (qu'est-ce que la "patrie» russe? quelles sont les spécificités des émigrations baltes, ukrainiennes ou cosaques?), politiques (quel régime pour la future Russie ?) et internationaux (quelles alliances ?).

2 Le livre de Michael Kellog, issu d'un $\mathrm{PhD}$ de l'université de Californie, s'attache à révéler les « racines russes du national-socialisme ", à travers l'étude de l'influence sur Hitler et le premier NSDAP d'un petit groupe d'émigrés, regroupés entre 1920 et 1923 en Bavière dans l'organisation Aufbau (Wirtschafts-politische Vereinigung für den Osten - Reconstruction: organisation politique et économique pour l'Est). L'auteur a travaillé sur la presse, les publications d'époque, les premiers discours de Hitler, mais a aussi dépouillé les archives de la Gestapo, du contre-espionnage et de la police secrète de Weimar, de la Sûreté 
générale et du $2^{e}$ Bureau français, de la police politique polonaise, les fonds privés de dirigeants nationalistes allemands, archives « trophées » récupérées par l'URSS après 1945 et conservées à Moscou aux anciennes « Archives spéciales " (désormais insérées dans les Archives militaires, ou RGVA). Michael Kellog propose un récit novateur et convaincant de la rencontre entre une partie de la droite völkisch allemande et de l'émigration blanche, « collaboration culturelle croisée » qui fut à la fois concrète et idéologique. Il retrace les moments successifs de cette rencontre (occupation de facto de l'Ukraine par les puissances centrales en 1918, croisade germano-blanche en Lettonie en 1919, putsch manqué de Kapp en 1920, tentatives d'assassinat de Kerenskij et Miljukov, enfin putsch de 1923 qui mènera Hitler en prison), en mettant l'accent sur les moyens (financement du NSDAP par le grandduc Kirill Romanov, contacts avec Wrangel) et les hommes. L'auteur insiste notamment sur le rôle des dirigeants de l'Aufbau, tous également membres du NSDAP : Alfred Rosenberg et Max von Scheubner-Richter, Baltes allemands membres de la Fraternité Livonia à l'université de Riga avant la Première Guerre mondiale, mais aussi Fedor Vinberg et Pëtr Šabel'skij-Bork, importateur en Allemagne des Protocoles des Sages de Sion. On suit avec intérêt l'ouvrage dans son analyse politique d'une alliance conspiratrice conclue sur les bases d'un combat anti-Entente, anti-Weimar, antibolchevik et antisémite. Il apporte également des éléments riches et précis à l'idée, déjà développée par exemple par Henri Rollin en 1939, puis par Walter Laqueur ou Ernst Nolte, selon laquelle les Russes blancs auraient apporté au nazisme la lecture apocalyptique de la menace mondiale juive concrétisée par la prise de pouvoir du judéo-bolchevisme en Russie, idée qui aurait été absente chez Hitler avant 1919. Le livre prolonge ainsi la « querelle des historiens » en suivant Ernst Nolte contre Daniel Goldhagen, sans toutefois pousser l'analyse jusqu'à établir des liens de causalité entre la perception du bolchevisme (peur née des récits de torture des tchékistes juifs et chinois, mais aussi admiration pour les méthodes centralisatrices et leçons tirées de l'élimination de l'intelligentsia) et l'antisémitisme nazi.

Pour autant, Michael Kellog, qui limite un peu vite les bases idéologiques de l'« extrême droite » russe à Dostoevskij et Solov'ëv, affaiblit son propos en ne le replaçant pas dans une analyse plus vaste des interactions intellectuelles russo-allemandes avant 1914, et en passant rapidement sur les points de divergence qui apparaissent dès les années 1920, à l'intérieur de l'extrême droite émigrée, mais aussi entre Hitler et ses alliés blancs, au sujet notamment de la place des Slaves dans le futur espace vital allemand. L'instrumentalisation des mouvements émigrés par le nazisme avant même son accession au pouvoir en 1933 et le rôle ambigu de Rosenberg auraient notamment mérité d'être développés.

Sur tous ces points, Meždu Rossiej i Stalinym, ouvrage collectif de dix auteurs dirigé par S. Karpenko - qui devrait en réalité être intitulé "Entre la Russie, Stalin et le fascisme »-, apporte bien des informations. Ce sont particulièrement les chapitres III (" Sous le signe de la svastika »), IV (« Le déclin de la ROVS ») et XI (« 'Drang nach Osten' sous le drapeau russe ») qui permettent de remettre en perspective l'Aufbau étudié par Michael Kellog dans une mouvance de la droite "russe " où les héritages politiques prérévolutionnaires et les enjeux du corpus idéologique fasciste ou antifasciste (cf. le chapitre consacré à la guerre d'Espagne) se superposent à l'alternative fondamentale qui traverse l'émigration russe pendant toute la période: priorité à l'indépendance nationale, ou priorité à la destruction du bolchevisme? Le premier choix fut celui des « défensistes » de l'entre-deux-guerres (à Paris la Sojuz Oborencev, devenue en 1936 le REOD, Mouvement de défense des émigrés russes) qui poussa nombre d'émigrés européens à souhaiter le retour dans la «patrie» soviétique et/ou à entrer dans la 
Résistance antinazie. Mais ce même sentiment national, opposé par les peuples du Caucase à l'impérialisme russe repris en héritage par l'URSS, entraîna une partie des mouvements cosaques dans la collaboration avec Hitler, jusqu'à l'épilogue tragique de la livraison de plusieurs dizaines de milliers d'entre eux à Stalin en 1945 au nom du « rapatriement " prévu par les accords de Potsdam. Quant au choix de la lutte « contre les bolcheviks, même avec le diable », il guida les multiples mouvements et partis du «fascisme russe » en Europe, aux États-Unis et en Chine, et fédéra une partie de l'Union des combattants russes (ROVS). Mais les divergences internes et la méfiance de Hitler envers une émigration slave unie freinèrent les dynamiques d'alliance, et ce n'est qu'en 1945 que le général Vlassov, transfuge de l'Armée rouge, fut autorisé à fédérer la totalité des forces militaires russes.

5 S'appuyant sur la richesse des fonds de l'émigration blanche aux Archives d'État de la Fédération de Russie (GARF), sans malheureusement préciser la nature des cotes citées ni a fortiori l'histoire de ces archives, l'ouvrage dirigé par S. Karpenko n'a pas l'ambition de proposer une synthèse, mais réussit, au fil de ses treize chapitres, à mettre l'accent sur la complexité des choix, en éclairant des moments clés comme le Pacte germanosoviétique et des épisodes connus (l'itinéraire de la mère Marie morte à Ravensbrück, la trahison de Vlassov) et moins connus, comme la présence russe dans les deux camps de la guerre d'Espagne ou la tentative des "solidaristes» des NTSNP (Union nationale du travail de la nouvelle génération) de trouver une troisième voie entre Hitler et Stalin, y compris en menant une propagande clandestine dans les camps de prisonniers soviétiques et chez les Ostarbeiter du Reich (chapitre XII). Tout comme Michael Kellog, les auteurs évoquent l'idée que les Blancs, tout au long de cette période, continuaient en quelque sorte « leur " guerre civile contre l'Armée rouge. Il est dommage qu'aucun des deux ouvrages ne s'appuie sur l'ensemble récent de travaux qui s'attachent à relire la Première Guerre mondiale et la guerre civile russe au prisme des politiques ethniques et de la notion de «brutalisation » mise en avant par George Mosse : ceci aurait sans doute permis d'éclairer tant l'absence de démobilisation culturelle et politique, si frappante tout au long de l'entre-deux-guerres, que les courants antisémites et militaristes d'une partie de l'émigration blanche. 